\title{
SYSTEM DYNAMICS AND AGENT-BASED SIMULATIONS FOR WORKFORCE CLIMATE
}

\author{
Mario Marin \\ Yanshen Zhu \\ American Technologika LLC \\ 37 North Orange Avenue, Suite 500 \\ Orlando , FL 32801, U.S.A.
}

\author{
Phillip T. Meade \\ Melissa Sargent \\ Julie Warren \\ KSC Organization Development \\ NASA, Kennedy Space Center \\ Orlando, FL, U.S.A.
}

\begin{abstract}
Many factors currently influence the NASA Kennedy Space Center (KSC) workforce, including the drive for return to flight, a stated Shuttle Program end date of 2010, and the Vision for Space Exploration which calls for the development of a new launch vehicle. Additionally, external factors such as cost of living in Central Florida, availability of skilled technical hires, and unemployment rate affect the overall workforce climate. Managing human capital in a manner consistent with safety and mission success, and to strategically position the center to execute its future mission, it is necessary to understand how these different influencing factors work together to produce an overall workforce climate. We have been using System Dynamics models to capture some of these factors. These models are also the starting point of agent-based models which can capture particular features not possible with the original system dynamics models. This paper introduces our simulation modeling efforts.
\end{abstract}

\section{INTRODUCTION}

This paper's motivation are the trends in the NASA enterprise environment toward more integration in systems and the increasing interest in simulation modeling approaches to managing enterprise systems. Managers are under increasing pressures to overcome the traditional organizational barriers and manage their systems in a more synchronized way. Yet managers are missing a decision-making tool to holistically model and analyze the management policies and performance of these systems. Such a decision-making tool needs to be simple to use, comprehensive, scalable, and able to model the varying levels of details and data availability which in turn, offer varying levels of analyses that fit the different levels of the enterprise. For example, a decision-making tool for workforce planning needs to encompass the strategic and tactical levels of decision making. Unlike other business enterprises the NASA KSC enterprise involves project and non-project activities. This implies different decision making frequencies and planning horizons and different needs for details in analyses and assessments. Above that, interactions and causeand-effect relationships among management levels and engineering units must be considered in modeling and analyzing the system performance.

We propose to build this decision-making tool for workforce climate, using a mixed modeling approach with system dynamics (SD) as the core to provide managers and decision-makers with a modeling and analysis level for workforce planning. SD is widely applied in different socioeconomic systems and recognizes, in particular, the roles of feedback information and the cause-and-effect relationships in creating the dynamic behaviors of the systems. It takes an integral perspective to modeling and analysis. As defined by its founder, SD is the study of the information feedback characteristics of a system to show how organizational structure, policies, and time delays in decisions and actions interact to create the system behavior. It treats the interactions between the flows of information, budget, motivation, personnel, and capital equipment in the enterprise system. It shifts the focus from individual decisions and entities to policies and system structure and it is not a datadriven technique. SD is very suitable for qualitative and continuous parameters in management decisions. In addition, the models are relatively easy to build and the complexity of a model seems to be increasing linearly as compared to other modeling methodologies.

\section{APPROACH}

Our main objective is to study the feasibility of developing a multiple-model system to enhance agency safety and mission success through a better understanding of the workforce health and climate.

The approach seeks to initially accomplish, the following:

- Collect and Analyze workforce Information. 


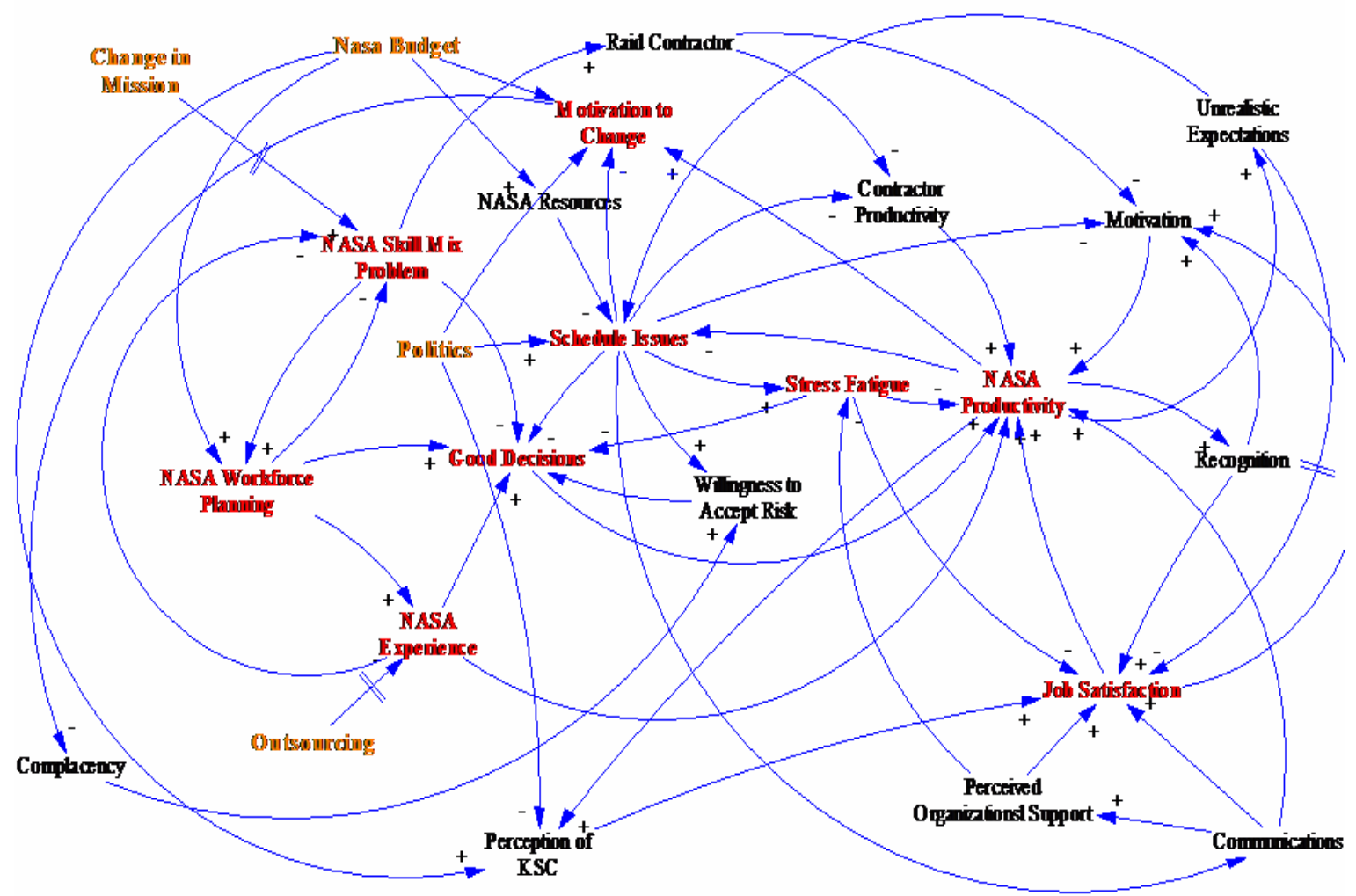

Figure 1. Aggregate Causal Loop

- Development of Causal Loops with Interdisciplinary Groups (Figure 1): There should be several sessions to develop a set of causal loops addressing the areas of: Aging Chain, Communication, Complacency, Contractors' Environment, Human Factors, Job Satisfaction, Knowledge, Motivation, Perception of KSC, and Schedule Pressure.

- Results will be taken and discussed with Subject Mater Experts outside the realm of KSC in order to obtain unbiased opinions and analyses. Our hope is to validate to the very minimum, the causal loops and arrive at some basic conclusions.

- Ascertain the state of the approach taken and the feasibility to accomplish the final objectives in subsequent phases, these assertion includes:

- The definition of a basic structure of the model program/project modeling and its respective pressures.

- The definition of a system architecture of the different potential space programs to be included in the final model.

Additionally, there should be project reports prepared and presented to top management: follow-on presentations which must include a basic System Dynamics Model using the aging chain concept.

\section{STATEMENT OF OBJECTIVES}

Based on the approach above, we propose to build a decision-making tool that simulates the NASA KSC workforce enterprise system. We will use data from different areas in order to provide views that support the analysis of different workforce strategies. Specifically, this work has the following objectives:

- Develop and deploy a comprehensive decisionmaking tool that managers can use to analyze different workforce planning strategies.

- Build comprehensive, multi-resolution, SD based models of the different areas of the NASA KSC workforce enterprise. These models will be related to work climates such as employee demographics, project environment/management, accidents, human factors, and the system architecture of space vehicles.

- The deployment of this decision-making tool will consider usability factors and integration/interface with other NASA KSC enterprise systems.

The decision-making tool will consist of several comprehensive simulation models for selected areas/dimensions of the workforce enterprise, especially at 
the strategy and operational levels of decision making. The following areas will be important for workforce planning (Figure 2):

- Workforce Demographics/Aging Chain: The characteristics of the workforce, training and mentoring, diversity, and the different hiring policies.

- System Architecture: The features of the missions, space vehicles, schedule, and how they map to operational/workforce requirements.

- Decision-Making: The different dynamics associated with decision-making. Mental models and cultural issues of safety and complacency are included in this area.

- Program/Project Environment: The project environment and the operational requirements along with the corresponding tasks and milestones to be accomplished. Scheduling pressures, fire-fighting, motivation, job satisfaction, and their effects on other areas are included.

- Supply Chain: The network of activities and agents required in the NASA enterprise. Knowledge, contractors, budget, resources, and employee development are important factors to be considered here.

The different models/areas will be interacting in an integrative feedback approach. Where a model should be used depends on the projected use of the model and the required level of details in the analysis. One potential enhancement of developing the enterprise simulation platform is the communication between the SD models and the workforce enterprise systems such that the models automatically exchange and share data while running. The significance of this is the ability to account for trends and the utilization of recent data/information.

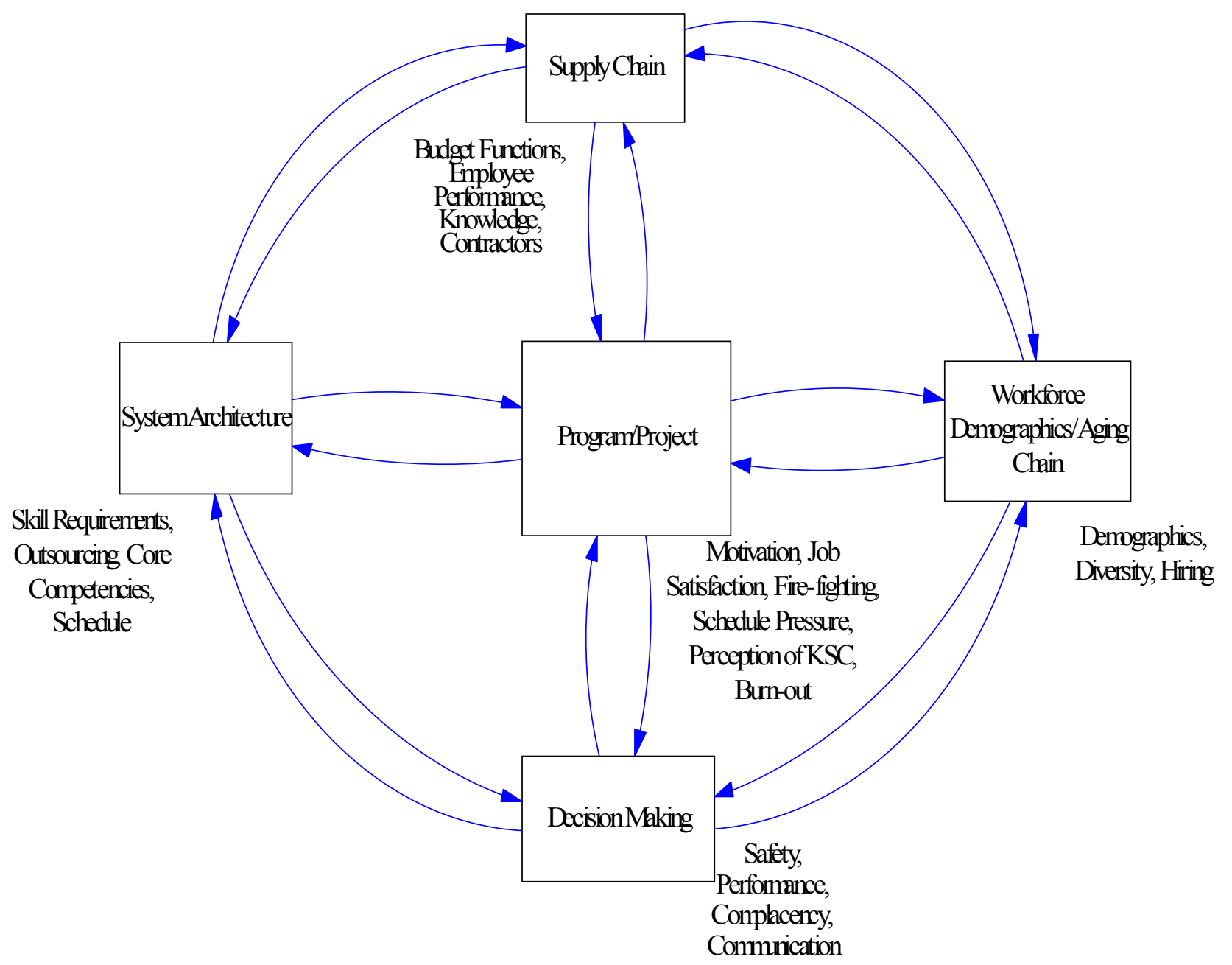

Figure 2. Areas and Their Interactions 
The different models/areas will be interacting in an integrative feedback approach. Where a model should be used depends on the projected use of the model and the required level of details in the analysis. One potential enhancement of developing the enterprise simulation platform is the communication between the SD models and the workforce enterprise systems such that the models automatically exchange and share data while running. The significance of this is the ability to account for trends and the utilization of recent data/information.

\section{SYSTEM DYNAMICS MODEL}

A system dynamics model is already built that demonstrates the aging of the workforce. This model has captured the different patterns of behavior of the employees. The model has more than 63 differential equations. A simulator using Anylogic is at the core of the simulation. However, the model originally was developed in the Vensin environment.

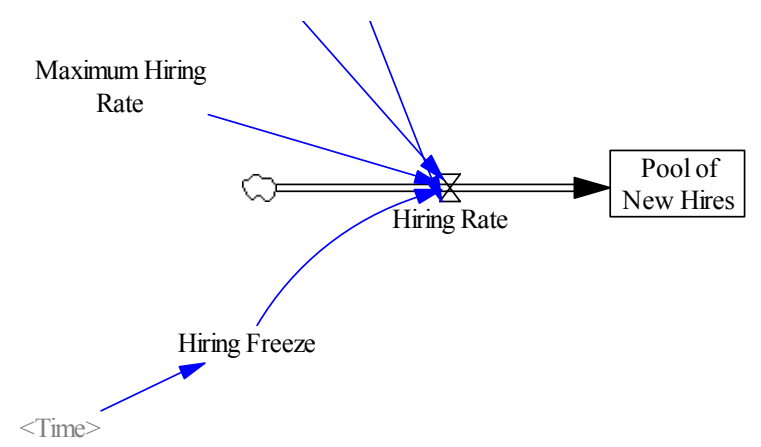

Figure 3. View of One of the Differential Equations of the Workforce Climate Model

\section{AGENTS-BASED MODEL}

An agent-based model was also built. The agent-based model was originally based on the system dynamics model. However, the agent representation allows for more complex behaviors. There are two types of basic agents: one represents an employee (e.g., a payload specialist) and the other one an employer (e.g., NASA KSC). This agentbased model was built using Anylogic.

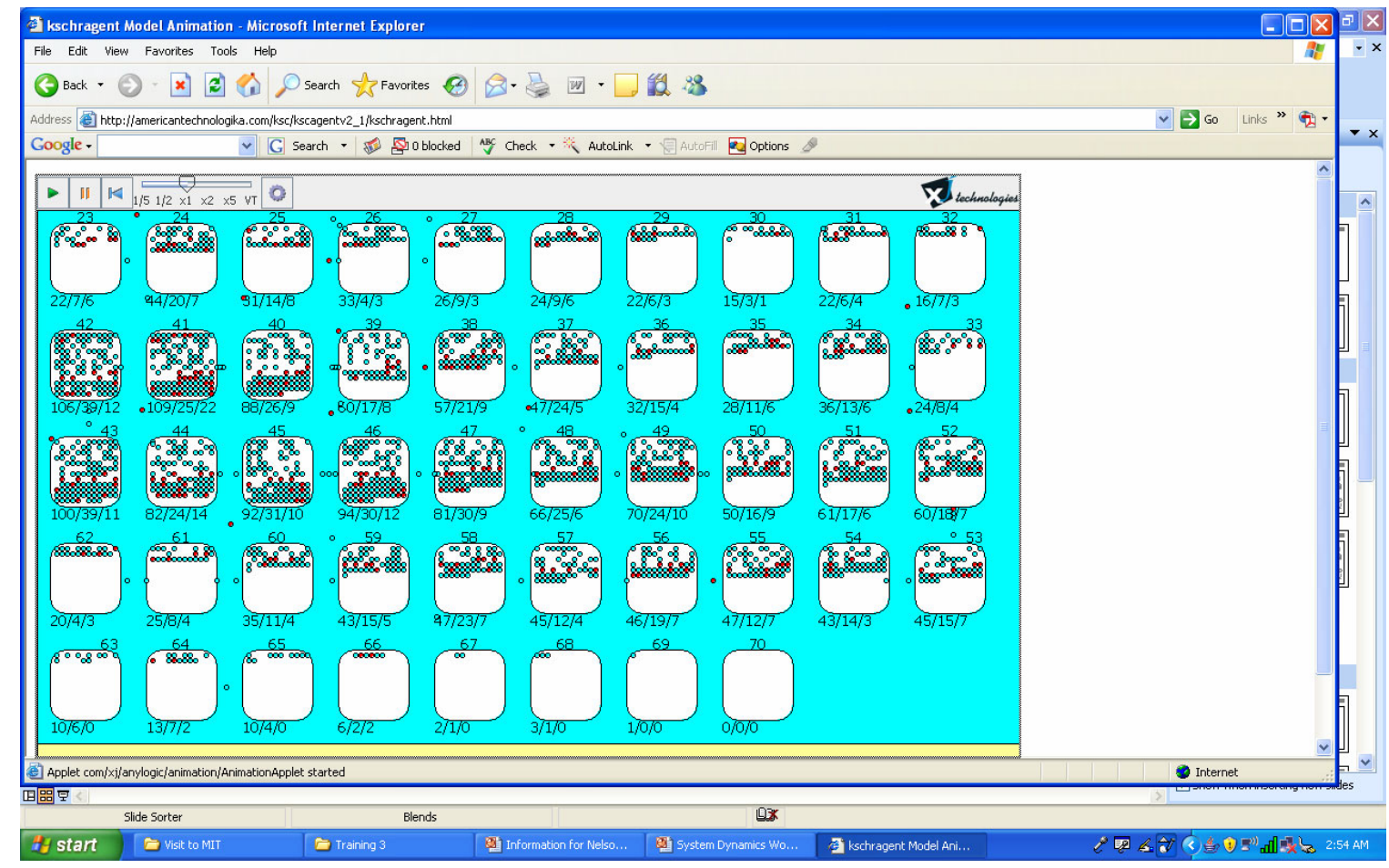

Figure 4. View of the Animation of the Agent-Based Model with Each Small Dot (Approximately 1,800 in this Figure) Representing an Employee 


\section{CONCLUSION}

The proposed comprehensive model will improve the communications between the top level decision-makers and the lower levels to the extent that we suggest strategic plans be subject to periodic adjustments and modification based on the feedback information from the lower level decision makers. This would increase the responsiveness of the NASA KSC workforce enterprise and its ability to provide proactive planning to avoid and/or overcome negative trends.

\section{ACKNOWLEDGMENTS}

We would like to recognize the excellent job done by the entire staff at the NASA KSC Organization Development Office and the entire staff at American Technologika.

\section{REFERENCES}

Linard, K. T., M. Blake, and D. Paterson. Optimising Structure the System Dynamics of Employment Planning.

Coyle, R. G. 1985. The Use of Optimization Methods for Policy Design in a System Dynamics Model, System Dynamics Review, Vol 1, No 1, Summer, pp. 81.

Coyle, R. G. 1996. System Dynamics Modelling, A Practical Approach, Chapman and Hall, pp. 236.

Sholtes, R. M. 1994. Optimising System Behaviour Using Genetic Algorithms, International System Dynamics Conference, Methodological and Technical Issues, pp. 246.

\section{AUTHOR BIOGRAPHIES}

MARIO MARIN, American Technologika CEO, received his Masters in Simulation Modeling and Analysis from the University of Central Florida. He is currently pursuing a Ph.D. in Industrial Engineering at the University of Central Florida. His research interests are mainly simulation integration of operations, HLA and XML technologies. His email is: <mariomarineamericantechnologika. com>.

PHILLIP T. MEADE, Ph.D., is the KSC Organization Development Manager . He received his Masters in Industrial Engineering and Ph.D. Industrial Engineering degrees from the University Central Florida. His main areas of research interest are object-oriented simulation, risk analysis, measuring and modeling training effectiveness, and applications of industrial engineering and simulation in change management. His e-mail address is: <Phillip.T. Meade@nasa.gov>.
MELISSA SARGENT is an Organization Development Specialist at KSC. She has an M.S in Industrial / Organizational Psychology from the University of Central Florida and is currently pursuing her Ph.D. Her primary area of research interest is around the measures and impacts of motivation on organizational performance. Her e-mail address is: <Melissa.J.Sargent@nasa.gov>.

JULIE WARREN is an Organization Development Specialist at KSC. She has an M.S in Industrial/Organizational Psychology from the Florida Institute of Technology and is currently pursuing her Ph.D. Her primary area of research interest is around knowledge management and the creation of mechanisms for ensuring knowledge requirements are met. Her e-mail address is: < Julie.A.Warren@nasa.

gov>.

YANSHEN ZHU is a Ph.D student at the School of Electrical Engineering and Computer Science of University of Central Florida where he received his M.S. degree in Computer Engineering in 2003. He received his B.S. degree in Computer Engineering from Wuhan University, China in 1998. He is a Reserach Scientist at American Technologika, his main interest are Systems Integration, Simulatiom Modeling and Conmputer programing. His email address is: <yanshen_zhu@americantechno logika.com>. 